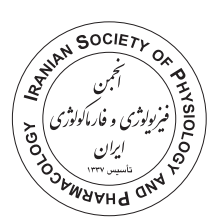

\title{
The impact of mild and short-term social stress on uri- nary levels of T3 and iodine in students of elementary schools
}

Sakineh Nouri Saeidlou ${ }^{1}$, Ehsan Saboory ${ }^{2,3^{*}}$ (D), Leila Derafshpour ${ }^{2}$, Sima Masudi ${ }^{4}, Z_{\text {Zafar Gholinejad }}^{5}$, Yousef Rasmi $^{5}$

1. Food and Beverages Safety Research Center, Urmia University of Medical Science, Urmia, Iran

2. Neurophysiology Research Center, Urmia University of Medical Sciences, Urmia, Iran

3. Zanjan Metabolic Diseases Research Center, Zanjan University of Medical Sciences, Zanjan, Iran

4. Department of Biostatistics and Epidemiology, School of Medicine, Urmia University of Medical Science, Urmia, Iran

5. Department of Biochemistry, School of Medicine, Urmia University of Medical Science, Urmia, Iran

\begin{abstract}
Introduction: Stress is a determinant factor in thyroid gland functions. A decrease in iodine concentration and thyroid hormones impairs cognitive functions in students. The responsiveness of thyroid hormones to stresses depends on many factors such as the intensity and duration of a particular stressor. This study aimed to examine the effect of mild and short-term social stress on heart rate (HR), blood pressure (BP), triiodothyronine (T3) and iodine concentrations of urine in students.

Methods: This controlled before-after study was conducted on 200 students aged 9-12 years (100 girls and 100 boys). The HR and BP of the students were measured and their urine samples were collected before and after the intervention in both stressed and control students. To induce stress, the students were asked to read aloud a text from their own book in front of some audience.

Results: In a mixed sample of girls and boys, a significant effect of stress was detected on BP and HR. There was no significant association between the stress and urinary level of T3 and iodine neither in girls nor in boys (and mixed sample). In girls, HR significantly increased in the stressed group while there was no significant connection between stress and BP. In boys, there was a significant difference between stress and control groups in terms of systolic and diastolic BP, but not the HR.

Conclusion: Although the stress had a significant sex-specific impact on HR and BP, urinary levels of $\mathrm{T} 3$ and iodine were not affected in elementary students.
\end{abstract}

\author{
Keywords: \\ Blood pressure \\ Elementary schools \\ Iodine \\ Metabolic adjustments \\ Social stress \\ $\mathrm{T} 3$
}

\section{Introduction}

Any intrinsic or extrinsic stimulus that evokes a biological response is known as stress (Yaribeygi et al., 2017). The effects of stress are known on numerous physiological processes such as endocrine, immune, central nervous system, cardiovascular responses, psychiatric disorders (McEwen, 2000). Stressful events can disrupt the normal regulation of neuroendocrine axes. Stress can be either acute or chronic. Acute stress lasts for a period of several minutes to hours, but chronic

\footnotetext{
* Corresponding author: Ehsan Saboory, saboory@zums.ac.ir

Received 22 July 2020; Revised from 7 October 2020; Accepted 27 October 2020
}

Citation: Nouri Saeidlou S, Saboory E, Derafshpour L, Masudi S, Gholinejad Z, Rasmi Y. The impact of mild and short-term social stress on urinary levels of T3 and iodine in students of elementary schools. Physiology and Pharmacology 2021; 25: 214-222. http://dx.doi.org/10.52547/ppj.25.3.214 
stress lasts for days to months and even life-long. It is expected that short-term social stress can acutely increase heart rate (HR) and blood pressure (BP), which are the primary outcomes of the current study. The stress level can determine the peak levels of stress hormones, neurotransmitters, and other physiological changes (e.g., increases in HR and BP), as well as the amount of time these changes persist during and following stressor exposure (Sephton et al., 2000). Psychological stress is more difficult to measure than the other stresses such as those associated with illness or exercise. What is stressful to one individual may not prove so to another. In this regard, physical and psychological stressors can activate the hypothalamic-pituitary-thyroid axis (Kyriacou et al., 2015). Fluctuations in thyroid hormones are linked to psychiatric disease (Baumgartner, 2000; Kyriacou et al., 2015), sexual behavior (Dellovade et al., 1996) and even evolution (Crockford, 2003). There are no conclusive results on whether stress reduces or increases thyroid hormones. An increase and decrease in thyroid hormone levels have been detected in immobilization (Turakulov et al., 1994), noise (Armario et al., 1984), lipopolysaccharide injection (Kondo et al., 1997) and escapable tail-shock (Servatius et al., 2000). Iodine is a trace element essential for thyroid hormone production that primarily received from the diet and excreted in the urine. This element plays a major role in the growth mechanisms and the development of tissues. The iodine status in children affects their mental performance. Low urinary iodine concentration in school children (7-11 y) has a significantly greater decrease in performance on the combination of mental tests (van den Briel et al., 2000). It has been reported that adequate iodine administration improves the memory capacity and reduces the level of anxiety and stress in school children (Magomeddibirova et al., 2017). Accurate measurement of dietary iodine intake from foods and water at a population level is a difficult task. In this regard, WHO/ICCIDD/ UNICEF recommends measurement of urinary iodine concentration (UIC) in evaluating population iodine nutrition (WHO, 2001). Indeed, UIC is a biomarker of goiter and thyroid functions (Zimmermann and Andersson, 2012). Although measuring UIC does not directly assess thyroid function, a deficient or an excessive median UIC in a population predicts a higher risk for the development of thyroid disorders. It is known that different stress models have different effects on thyroid function and the level of thyroid hormones. Moreover, students in the age of elementary school (7-12 y) have a rapidly developing brain. Stress affects the developing brain of these children more severely than that of adults (Saboory et al., 2019). Therefore, evaluating common stressful events at this age can be useful for expanding our understanding to better involve in teaching and growing up these students. Generally, presentations and/ or giving a lecture in a meeting can be stressful even for expert adults and even might be more stressful in elementary students. This is sometimes referred to as performance anxiety (Chorpita and Barlow, 1998). In the present study, we used this method to induce stress in students. However, previous literature does not clearly relate certain effects to each specific stress model and the role that stressors may play in modulating levels of other hormones, especially during development while the brain and body continue to mature. Therefore, this work was designed to expand our current understanding in this context. This study is an attempt to assess the impact of mild and short-term social stress on urinary levels of triiodothyronine (T3) and iodine in elementary school. We hypothesized that the stress procedure alters urinary levels of $\mathrm{T} 3$ and iodine.

\section{Methods and Materials}

\section{Ethical approve}

The present research was approved by the Ethics Committee of the Urmia University of Medical Sciences (ID: IR.XMSU.REC.1395.435) and registered at the Iran Registry of Clinical Trials under IRCT20171015036779N2.

\section{Participants}

This controlled before-after study was conducted among elementary school students in Urmia, the capital of West Azarbyjan, Iran. A written informed consent was obtained from the parents of the students. In total, 200 students with age range of 9-12 years (100 girls and 100 boys) were selected using a simple random sampling method with replacement from the list of students in grades 4 to 6 in two elementary schools. It is of note that all the schools are single-sex in Iran. The students who had any recognized illness and drug take in the past two months, as well as family problems including parental divorce, death of parents and relatives during the past six months were not included in the study. 


\section{Randomization}

To assign 100 students to the intervention groups in each school, a block randomization method with a block size of four was used to divide the students into stress and control groups. This randomization method was performed to yield a balanced number of students in two groups. The blocks and their random order were defined before the random selection of students. At each elementary school, the list of all students of fourth, fifth and sixth grade was obtained from school officials. Afterward, an identification number from 1 to $\mathrm{N}$ was assigned to each student. Then, using a table of random numbers, 100 students were selected from each school. We considered a $20 \%$ chance of not agreeing to participate in the study either by the students or their parents. The selection order of the students was recorded. After obtaining the informed consent from the parents of the students, we matched the selection order of the students with the predefined order of the blocked randomization to identify the group that the students were assigned to. Student characteristics including their height, weight, schooling score, age, education of their parents and their mothers' disease history were obtained through interviews with students and their mothers, simultaneously. Mothers completed a questionnaire on their stress status based on Cohen's perceived stress score. The HR and BP of the students were measured before and after the intervention in both stressed and control groups. All students in the stressed group were requested to provide a urine sample before the intervention and urine sample $2 \mathrm{~h}$ after the intervention. The students in the control group provided two urine samples with a similar time course as the stress group without any intervention. All urine samples were taken between 9:00am and 12 midday.

\section{Stress procedures}

Before calling the students to the stress room, their $\mathrm{HR}$ and BP were measured in sitting position at the classroom in the presence of other students. Then, after 15-30min, the students were guided to the stress room two at a time. The students were asked to read aloud a text from their own book for $3 \mathrm{~min}$. The text and poetry were selected from a portion of the book that was unfamiliar for children (confirmed by their teacher). This procedure was performed in the school principal's room with the presence of parents, teachers, school adminis- trators and at least two members of the current research team. Students were called, two at a time, to a table at the front of the room. They were asked to stay quiet for the first $2 \mathrm{~min}$ and then read aloud the selected text for $3 \mathrm{~min}$ in standing position. Next, they again were asked to stay quiet for another $2 \mathrm{~min}$ in sitting position. Afterward, the HR and BP of students were measured in the sitting position and their systolic, diastolic and HR were recorded (Gholami and Saboory, 2013). For measuring HR, we put the tips of our little and ring finger on the medial side of the student's wrist and count the number of pulses per minute. Moreover, to measure blood pressure, a sphygmomanometer (Health-Ace Model: 501-V) and a stethoscope (ALP K2, Capes medical, New Zealand) were used.

Spot urine samples were collected and delivered to the laboratory for measuring UIC. The UIC was determined by the modified acid-digestion method (Dunn et al., 1993). In this study, the colorimetric ceric-arsenic assay, which yields the colorless cerium and arsenic, was used for measuring urinary iodine. This assay is a twostep reaction where the rate of the reaction is measured during the reduction of the yellow-colored ceric ions by arsenic in the presence of iodide to form the colorless cerous ions and elemental iodine.

The reduction in the yellow cerium was measured spectrophotometrically at $405 \mathrm{~nm}$. Some of the students were unable to provide a urine sample before the intervention or after it. Also, in some cases, the volume of the samples was not sufficient. The analysis was performed using the data of students who had two successful measures of urine iodine and T3. Totally, 138 students remained in the analysis, of which 41 girls and 32 boys were assigned to the control group and 41 girls and 24 boys to the stressed group.

\section{Statistical analysis}

Quantitative variables were reported as means and standard deviations and qualitative variables were reported in percentage. The Kolmogorov-Smirnov test was used to determine the normality of distribution. Chi-square and independent t-test were used to compare the baseline characteristics of the students in control and stressed groups. We used the one-way analysis of covariance (ANCOVA) to compare the effect of mild social stress on the outcome variables whilst controlling their baseline measurements. We used a natural log transfor- 
mation of the variable with non-normal distribution. Leven's test was used to check the assumption of the equality of variances. The results showed that this assumption was met in our data. We reported the effect size of the intervention for each variable based on partial eta squares estimated in the results of analysis of covariance. An effect size equal to $0.2,0.5$ and 0.8 is considered as small, medium and large effect size, respectively. Data analysis was performed using SPSS version 20 (SPSS Inc., Chicago, IL). Differences with $P<0.05$ were considered statistically significant.

\section{Results}

The baseline characteristics of the stressed and control groups are shown in Table 1. No statistically significant differences were identified between the two groups. Since, the students of both groups were in similar age and gender groups, these variables were not reported in Table 1. Several students either were unable to provide a urine sample or the volume of the samples was not sufficient. So, they were removed from the data analysis. Finally, 138 students remained in the analysis, of which
$41(63.1 \%)$ girls and $32(36.9 \%)$ boys were assigned to the control group and 41 (56.2\%) girls and $24(43.8 \%)$ boys to the stressed group.

The results of one-way ANCOVA showed no significant difference between control and stressed groups in terms of urinary T3 and iodine concentration. But, a significant effect of stress was detectedon PR, systolic and diastolic BP after controlling for their baseline measures, although the baseline values were associated with their after-stress levels ( $P<0.05$, Table 2$)$.

In girls, there was no significant difference between stressed and control groups in terms of urinary T3 and iodine concentration, systolic and diastolic BP. The baseline measures (before stress) of these variables (except T3) were associated with after stress values of them. In comparison, stress had a significant effect on pulse rate after controlling for its baseline measures, although baseline valueswere associated with post-stressmeasures $(P<0.05$, Table 3$)$.

In boys, there was a significant difference between stressed and control groups in terms of systolic and diastolic $\mathrm{BP}(P=0.002$ and $P=0.022$, respectively). Howev-

TABLE 1: Comparison of the baseline characteristics of participants between two groups.

\begin{tabular}{|c|c|c|c|c|}
\hline \multirow[t]{2}{*}{ Variables" } & & Control & Stressed & \multirow[t]{2}{*}{$P$-value ${ }^{* * *}$} \\
\hline & & Means \pm SD & Means \pm SD & \\
\hline Height (cm) & & $146.72 \pm 10.10$ & $146.61 \pm 8.71$ & 0.945 \\
\hline Weight (kg) & & $44.72 \pm 14.4$ & $44.45 \pm 13.1$ & 0.911 \\
\hline Schooling score & & $17.61 \pm 2.3$ & $17.14 \pm 3.39$ & 0.363 \\
\hline Mother age & & $37.47 \pm 5.64$ & $36.66 \pm 5.97$ & 0.444 \\
\hline \multirow[t]{2}{*}{ Mother stress score } & & $22.96 \pm 7.09$ & $22.20 \pm 7.99$ & 0.577 \\
\hline & & $\mathrm{N} \quad \%$ & $\mathrm{~N} \quad \%$ & \\
\hline \multirow[t]{2}{*}{ Sex } & Girls & $41(63.1)$ & $41(56.2)$ & \multirow{2}{*}{0.409} \\
\hline & Boys & $32(36.9)$ & $24(43.8)$ & \\
\hline \multirow[t]{2}{*}{ Child's disease } & No & $69(87.5)$ & $56(94.5)$ & \multirow{2}{*}{0.147} \\
\hline & yes & $4(12.5)$ & $8(5.5)$ & \\
\hline \multirow{2}{*}{$\begin{array}{l}\text { Drug use } \\
\text { by children }\end{array}$} & No & $71(97.3)$ & $60(95.2)$ & \multirow{2}{*}{0.532} \\
\hline & yes & $2(4.8)$ & $3(2.7)$ & \\
\hline \multirow[t]{2}{*}{ Mother's disease } & No & $54(75.0)$ & $54(87.1)$ & \multirow{2}{*}{0.077} \\
\hline & yes & $18(25.0)$ & $8(12.9)$ & \\
\hline \multirow[t]{2}{*}{ Drug use by the mother } & No & $57(79.2)$ & $51(82.3)$ & \multirow{2}{*}{0.652} \\
\hline & yes & $15(20.8)$ & $11(17.7)$ & \\
\hline \multirow[t]{2}{*}{ Mother's education } & Diploma or less & $50(64.9)$ & $41(67.2)$ & \multirow{2}{*}{0.782} \\
\hline & Collegiate & $22(35.1)$ & $20(32.8)$ & \\
\hline
\end{tabular}

"Values are means $\pm \mathrm{SD}, \mathrm{N}(\%)$

${ }^{* *} P$-values were obtained by independent sample t-test and chi-square test methods 
TABLE 2: The results of the analysis of covariance test for all participants (school children, mixed girls and boys).

\begin{tabular}{|c|c|c|c|c|c|c|}
\hline Variables & Group & Before intervention & After intervention & $\begin{array}{c}\text { Difference } \\
\text { scores }\end{array}$ & $\begin{array}{l}\text { Observed } \\
\text { effect size }\end{array}$ & $P$-value \\
\hline \multirow{2}{*}{ Systolic BP } & Control & $100.2(14.2)$ & $95.7(14.9)$ & -4.5 & \multirow[t]{2}{*}{0.065} & \multirow[t]{2}{*}{0.003} \\
\hline & Stressed & 101.9(11.9) & $102.3(13.3)$ & 0.4 & & \\
\hline \multirow{2}{*}{ Diastolic BP } & Control & $61.0(9.7)$ & $59.0(10.9)$ & -2.1 & \multirow[t]{2}{*}{0.035} & \multirow[t]{2}{*}{0.028} \\
\hline & Stressed & $61.6(9.9)$ & $63.0(10.2)$ & 0.7 & & \\
\hline \multirow{2}{*}{ Pulse rate } & Control & $88.4(11.8)$ & $88.3(14.4)$ & -0.09 & \multirow[t]{2}{*}{0.103} & \multirow[t]{2}{*}{$<0.001$} \\
\hline & Stressed & $91.6(13.9)$ & $98.3(13.9)$ & 6.68 & & \\
\hline \multirow{2}{*}{$\begin{array}{l}\text { Urinary iodine }(\mu \mathrm{g} / \\
\mathrm{dl})\end{array}$} & Control & $16.2(10.7)$ & $14.1(9.4)$ & -2.07 & \multirow[t]{2}{*}{0.020} & \multirow[t]{2}{*}{0.098} \\
\hline & Stressed & $16.9(12.1)$ & $17.2(12.2)$ & 0.34 & & \\
\hline \multirow{2}{*}{ Urinary T3 (ng/dl) } & Control & $3.45(0.24)$ & $3.69(2.15)$ & 0.24 & \multirow[t]{2}{*}{0.006} & \multirow[t]{2}{*}{0.382} \\
\hline & Stressed & $3.68(1.9)$ & $3.55(1.93)$ & -0.15 & & \\
\hline
\end{tabular}

TABLE 3: The results of the analysis of covariance for girl students.

\begin{tabular}{|c|c|c|c|c|c|c|}
\hline Variables & Group & Before intervention & $\begin{array}{c}\text { After the } \\
\text { intervention }\end{array}$ & $\begin{array}{c}\text { Difference } \\
\text { scores }\end{array}$ & $\begin{array}{l}\text { Observed } \\
\text { effect size }\end{array}$ & P-value \\
\hline \multirow[t]{2}{*}{ Systolic BP } & Control & $101.68(15.39)$ & $99.83(13.55)$ & -1.85 & 0.016 & 0.256 \\
\hline & Stressed & 102.66(11.95) & $103.17(13.09)$ & 0.51 & & \\
\hline \multirow{2}{*}{ Diastolic BP } & Control & $59.85(10.17)$ & $60.78(11.29)$ & 0.93 & 0.007 & 0.456 \\
\hline & Stressed & $62.78(10.99)$ & 63.76(11.39) & 0.98 & & \\
\hline \multirow[t]{2}{*}{ Pulse rate } & Control & $92.24(12.08)$ & $90.80(15.09)$ & -1.44 & 0.130 & 0.001 \\
\hline & Stressed & $90.15(14.70)$ & $100.66(14.09)$ & 10.51 & & \\
\hline Urinary & Control & $19.39(11.80)$ & $15.11(10.01)$ & -4.28 & 0.008 & 0.425 \\
\hline iodine $(\mu \mathrm{g} / \mathrm{dl})$ & Stressed & $19.70(11.30)$ & $17.78(12.38)$ & -1.91 & & \\
\hline Urinary & Control & $3.01(1.50)$ & $3.06(1.85)$ & 0.06 & 0.013 & 0.312 \\
\hline T3(ng/dl) & Stressed & $3.33(1.76)$ & $2.92(1.80)$ & -0.43 & & \\
\hline
\end{tabular}

er, stress did not showany significant effect onurinary T3 and iodine levels whilst controlling for their pre-intervention level. The baseline values of all variables were associated with the post-stress level of them $(P<0.05$, Table 4).

\section{Discussion}

In the current study, the effect of mild and short-term social stress was examined on HR, BP, urinary T3 and iodine levels in a sample of elementary school students. The social stress procedure induced only changes in cardiovascular parameters that are adaptive physiological responses. New to our study and contrary to our original hypotheses, endocrinological parameters were not affected in stressed students. In other words, stress has significant effects on BP and HR and no significant effect in terms of urinary $\mathrm{T} 3$ and iodine concentration.

Social stress, defined as the set of physiological stress responses specifically caused by the presence and actions of certain conspecifics, has repeatedly been shown to predict BP and cardiovascular disease (Smith et al., 2012). The association between experience of social-evaluative threat during the day and an increase in BP is proven (Kamarck et al., 2005). A pattern of autonomic activity during acute stress can be a mediator of changes of BP and HR in which both beta-adrenergic sympathetic activation and vagal withdrawal are involved to a roughly equal extent (Brindle et al., 2014). In the current study, the effect of mild and short-term social stress on BP (in boys) and HR (in girls) was statis- 
TABLE 4: The results of the analysis of covariance for boy students.

\begin{tabular}{|c|c|c|c|c|c|c|}
\hline Variables & Group & Before intervention & $\begin{array}{c}\text { After the } \\
\text { intervention }\end{array}$ & $\begin{array}{c}\text { Difference } \\
\text { scores }\end{array}$ & $\begin{array}{l}\text { Observed } \\
\text { effect size }\end{array}$ & $P$-value \\
\hline \multirow{2}{*}{ Systolic BP } & Control & $98.34(12.56)$ & $90.44(15.24)$ & -7.90 & \multirow{2}{*}{0.166} & \multirow{2}{*}{0.002} \\
\hline & Stressed & $100.67(11.82)$ & $100.88(132.85)$ & 0.21 & & \\
\hline \multirow{2}{*}{ Diastolic BP } & Control & $62.47(9.03)$ & $56.59(10.09)$ & -5.88 & \multirow{2}{*}{0.094} & \multirow[t]{2}{*}{0.022} \\
\hline & Stressed & $61.25(7.82)$ & $61.58(7.82)$ & 0.33 & & \\
\hline \multirow{2}{*}{ Pulse rate } & Control & $83.56(9.46)$ & $85.19(13.05)$ & 1.63 & \multirow{2}{*}{0.013} & \multirow{2}{*}{0.415} \\
\hline & Stressed & $94.17(12.38)$ & $94.29(12.88)$ & 0.13 & & \\
\hline \multirow{2}{*}{$\begin{array}{l}\text { Urinary iodine }(\mu \mathrm{g} / \\
\text { dl) }\end{array}$} & Control & $12.09(7.50)$ & $12.45(8.45)$ & 0.75 & \multirow{2}{*}{0.057} & \multirow{2}{*}{0.080} \\
\hline & Stressed & $12.12(12.23)$ & $16.31(12.12)$ & 4.19 & & \\
\hline \multirow{2}{*}{ Urinary T3 (ng/dl) } & Control & $4.03(1.70)$ & $4.49(2.28)$ & 0.46 & \multirow{2}{*}{0.009} & \multirow{2}{*}{0.497} \\
\hline & Stressed & $4.28(2.02)$ & $4.61(1.69)$ & 0.33 & & \\
\hline
\end{tabular}

tically significant. It has been reported that in physiological responses to acute behavioral stressors, boys exhibit a significant increase in BP and sympathetic responses to a challenge compared to girls (Brindle et al., 2014). On the other hand, girls have larger heart rate responses to the videotaped speech task as an acute stressor compared to boys (Kudielka et al., 2004). Meanwhile, a study reported sex differences in both systolic and diastolic BP responses during stress among middle-aged subjects, but not among children (Matthews and Stoney, 1988). However, sex differences in BP and HR are highly dependent upon the nature of the task and stressor (Matthews and Stoney, 1988). The boys who experience annoyance or anger in school often hide these feelings; this may be the cause of elevations of BP in stress reactivity. Overall, further research is needed to understand the mechanisms linking sex to BP and HR in mild and short-term social stress. The results of this study are consistent with the findings of others confirming the six specific effects of stress in many subjects including rats and humans (Gholami and Saboory, 2013; Gholipoor et al., 2017; Saboory et al., 2019).

A decrease in the activity of the thyroid gland can be yielded through stressing agents (Bogoroch and Timiras, 1951). Namely, when cortisol levels change through a stressful situation, a negative relationship is found between cortisol and thyroid stimulating hormone (Samuels and McDaniel, 1997). However, we did not find any change of urinary T3 and iodine concentration in response to the stress. In the current study, the values of urinary iodine levels were in normal range according to WHO standards (10-19.9 $\mu \mathrm{g} / \mathrm{dl})$; there was no reliable reference for urinary T3 level (WHO, 2001), therefore, we could not compare it with other studies.

Nevertheless, there is a wide range of stressors to induce a decrease in T3 levels in restraint (Bianco et al., 1987), fasting (Boelen et al., 2008) and heat stress (Etches et al., 2008). Likely, the change of T3 levels may be seen after long-term exposure to a stressor (Hangalapura et al., 2004). A slight increase or no change in peripheral thyroid hormone levels may be caused by mild stressors (Turakulov et al., 1994); which may explain our results. A mild decrease in urinary iodine content is likely following exposure to severe stress. However, no significant changes were observed in the current study after stress, probably due to the mild intensity and short duration of applied stress in our study. Acute stress may be considered as a factor activating iodide content in the thyroid gland. Nevertheless, the univocal solution to this problem requires further investigations because of the multilevel effects of glucocorticoids on thyroid homeostasis (Nadolnik, 2012). We examined the effect of acute social stress on iodine and T3 levels after $120 \mathrm{~min}$ of stress exposure whereas the adjustment of thyroid hormone levels to a new condition may require more time. One limitation of our study is a single time course of urine sampling (120min after stress exposure). Although there are reports that $120 \mathrm{~min}$ interval between stressor exposure and urine sample can be sufficient to detect the changes in urinary iodine levels, trying different time 
courses (which was not done in this study) can be helpful. Our study had another critical limitation; we had to exclude those students from data analysis that could not complete the second urine sampling and/or those with a too low urine volume. This exclusion decreased the sample size and likely affected the obtained results.

The effects of severe iodine deficiency on neurological development have been well documented. It has been reported that chronic moderate-to-severe iodine deficiency, particularly in children, reduces IQ by about 12-13.5 points (Zimmermann, 2009). A 2004 Cochrane review concluded that iodine supplementation in children living in areas of iodine deficiency appears positively affect physical and mental development and decrease mortality with only minor and transient adverse effects (Angermayr and Clar, 2004). The effects of mild iodine deficiency during childhood are more difficult to quantify. Some studies suggest that mild iodine deficiency is associated with subtle neurodevelopmental deficits and that iodine supplementation might improve cognitive function in mildly iodine-deficient children (Melse-Boonstra and Jaiswal, 2010). In a study, 184 children aged 10-13 years in New Zealand with a median UIC of $63 \mu \mathrm{g} / \mathrm{l}$ received iodine supplements $(150 \mu \mathrm{g} /$ day $)$ or placebo for 28 weeks (Gordon et al., 2009). Iodine supplementation improved iodine status and significantly improved measures of perceptual reasoning and overall cognitive score compared with children taking a placebo. These findings suggest that correcting mild iodine deficiency in children could improve certain components of cognition. In the current study, students' learning score was obtained from their schools but there was no correlation between the scores and iodine and T3 levels (data not shown). The current study is unique from this point of view that we studied elementary school students with both sexes (girls and boys) simultaneously in the same region of a city (homogeny sample) and with exactly the same method, separately. To the best of authors' knowledge, in most parts of the world, elementary schools are mixed-sex education-based. But, in Iran, all the schools, including elementary schools, are single-sex. Thus, this condition as a strength of this study lets us examine the girls and boys in separate environments.

\section{Conlcusion}

It can be concluded that exposure to mild and shortterm stress such as a presentation in a small meeting has sufficient power to activate the stress response in elementary students, as shown by increased HR and BP. However, the intensity of such stressors is not sufficient to produce detectable changes in the urinary content of iodine and T3. We suggest conducting similar studies with greater sample size and different time courses (e.g., 60-240min) between stress exposure and urine sampling.

\section{Conflict of interest}

The authors declare no conflicts of interest.

\section{Acknowledgment}

This study was supported by the Urmia University of Medical Sciences, Urmia, Iran.

\section{References}

Angermayr L, Clar C. Iodine supplementation for preventing iodine deficiency disorders in children. Cochrane Database Syst Rev 2004: Cd003819. https://doi. org/10.1002/14651858.CD003819.pub2

Armario A, Castellanos JM, Balasch J. Effect of acute and chronic psychogenic stress on corticoadrenal and pituitary-thyroid hormones in male rats. Horm Res Paediatr 1984; 20: 241-5. https://doi.org/10.1159/000180003

Baumgartner A. Thyroxine and the treatment of affective disorders: an overview of the results of basic and clinical research. Int J Neuropsychopharmacol 2000; 3: 149-65. https://doi.org/10.1017/S1461145700001887

Bianco AC, Nunes MT, Hell NS, Maciel RM. The role of glucocorticoids in the stress-induced reduction of extrathyroidal 3, 5, 3'-triiodothyronine generation in rats. Endocrinology 1987; 120: 1033-8. https://doi.org/10.1210/endo120-3-1033

Boelen A, Wiersinga WM, Fliers E. Fasting-induced changes in the hypothalamus-pituitary-thyroid axis. Thyroid 2008; 18: 123-9. https://doi.org/10.1089/thy.2007.0253

Bogoroch R, Timiras P. The response of the thyroid gland of the rat to severe stress. Endocrinology 1951; 49: 548-56. https://doi.org/10.1210/endo-49-4-548

Brindle RC, Ginty AT, Phillips AC, Carroll D. A tale of two mechanisms: a meta-analytic approach toward understanding the autonomic basis of cardiovascular reactivity to acute psychological stress. Psychophysiology 2014; 51: 964-76. https://doi.org/10.1111/psyp.12248

Chorpita BF, Barlow DH. The development of anxiety: the role of control in the early environment. Psychol Bull 1998; 
124: 3-21. https://doi.org/10.1037/0033-2909.124.1.3

Crockford SJ. Thyroid rhythm phenotypes and hominid evolution: a new paradigm implicates pulsatile hormone secretion in speciation and adaptation changes. Comp Biochem Physiol A Mol Integr Physiol 2003; 135: 105-29. https:// doi.org/10.1016/S1095-6433(02)00259-3

Dellovade TL, Zhu YS, Krey L, Pfaff DW. Thyroid hormone and estrogen interact to regulate behavior. Proc Natl Acad Sci USA 1996; 93: 12581-6. https://doi.org/10.1073/ pnas.93.22.12581

Dunn JT, Crutchfield HE, Gutekunst R, Dunn AD. Two simple methods for measuring iodine in urine. Thyroid 1993; 3: 119-23. https://doi.org/10.1089/thy.1993.3.119

Etches RJ, John TM, Gibbins AV. Behavioural, physiological, neuroendocrine and molecular responses to heat stress. Poultry Production in Hot Climates 2008; p. 31-66.

Gholami M, Saboory E. Morphine exposure induces age-dependent alterations in pentylenetetrazole-induced epileptic behaviors in prepubertal rats. Dev Psychobiol 2013; 55: 881-7. https://doi.org/10.1002/dev.21080

Gholipoor P, Saboory E, Ghazavi A, Kiyani A, Roshan-Milani S, Mohammadi S, et al. Prenatal stress potentiates febrile seizure and leads to long-lasting increase in cortisol blood levels in children under 2 years old. Epilepsy Behav 2017; 72: 22-7. https://doi.org/10.1016/j.yebeh.2017.04.021

Gordon RC, Rose MC, Skeaff SA, Gray AR, Morgan KM, Ruffman T. Iodine supplementation improves cognition in mildly iodine-deficient children. Am J Clin Nutr 2009; 90: 1264-71. https://doi.org/10.3945/ajcn.2009.28145

Hangalapura BN, Nieuwland MG, Buyse J, Kemp B, Parmentier HK. Effect of duration of cold stress on plasma adrenal and thyroid hormone levels and immune responses in chicken lines divergently selected for antibody responses. Poult Sci J 2004; 83: 1644-9. https://doi.org/10.1093/ ps/83.10.1644

Kamarck TW, Schwartz JE, Shiffman S, Muldoon MF, Sutton-Tyrrell K, Janicki DL. Psychosocial stress and cardiovascular risk: what is the role of daily experience? J Pers 2005; 73: 1749-74. https://doi.org/10.1111/j.00223506.2005.00365.x

Kondo K, Harbuz MS, Levy A, Lightman SL. Inhibition of the hypothalamic-pituitary-thyroid axis in response to lipopolysaccharide is independent of changes in circulating corticosteroids. Neuroimmunomodulation 1997; 4: 188-94. https://doi.org/10.1159/000097337

Kudielka BM, Buske-Kirschbaum A, Hellhammer DH, Kirschbaum C. Differential heart rate reactivity and re- covery after psychosocial stress (tsst) in healthy children, younger adults, and elderly adults: the impact of age and gender. Int J Behav Med 2004; 11: 116-21. https://doi. org/10.1207/s15327558ijbm1102_8

Kyriacou A, McLaughlin J, Syed AA. Thyroid disorders and gastrointestinal and liver dysfunction: a state of the art review. Eur J Intern Med 2015; 26: 563-71. https://doi. org/10.1016/j.ejim.2015.07.017

Magomeddibirova ZA, Tazutdinova GS, Magomedkhanova US, Kurbanova AB, Asadulaeva FR, Abdurakhmanova AG. The influence of adequate iodine intake on the level of stress resistance and the capacity of short-term memory in schoolchildren. J Pharm Sci Res 2017; 9: 904-9.

Matthews KA, Stoney CM. Influences of sex and age on cardiovascular responses during stress. Psychosom Med 1988; 50: 46-56. https://doi.org/10.1097/00006842-19880100000006

McEwen BS. Allostasis and allostatic load: Implications for neuropsychopharmacology. Neuropsychopharmacology 2000; 22: 108-24. https://doi.org/10.1016/S0893133X(99)00129-3

Melse-Boonstra A, Jaiswal N. Iodine deficiency in pregnancy, infancy and childhood and its consequences for brain development. Best Pract Res Clin Endocrinol Metab 2010; 24: 29-38. https://doi.org/10.1016/j.beem.2009.09.002

Nadolnik L. Role of glucocorticoids in regulation of iodine metabolism in thyroid gland: effects of hyper-and hypocorticism. Glucocorticoids-new recognition of our familiar friend. InTech. 2012; 28: 265-302. https://doi. org/10.5772/52043

Saboory E, Mohammadi S, Dindarian S, Mohammadi H. Prenatal stress and elevated seizure susceptibility: Molecular inheritable changes. Epilepsy Behav 2019; 96: 122-131. https://doi.org/10.1016/j.yebeh.2019.04.046

Samuels MH, McDaniel PA. Thyrotropin levels during hydrocortisone infusions that mimic fasting-induced cortisol elevations: A clinical research center study. J Clin Endocrinol Metab 1997; 82: 3700-4. https://doi.org/10.1210/ jc.82.11.3700

Sephton SE, Sapolsky RM, Kraemer HC, Spiegel D. Early mortality in metastatic breast cancer patients with absent or abnormal diurnal cortisol rhythms. J Natl Cancer Inst 2000; 92: 994-1000. https://doi.org/10.1093/jnci/92.12.994

Servatius RJ, Natelson BH, Moldow R, Pogach L, Brennan FX, Ottenweller JE. Persistent neuroendocrine changes in multiple hormonal axes after a single or repeated stressor exposures. Stress 2000; 3: 263-74. https://doi. 
org/10.3109/10253890009001132

Smith TW, Birmingham W, Uchino BN. Evaluative threat and ambulatory blood pressure: cardiovascular effects of social stress in daily experience. Health Psychol 2012; 31: 763. https://doi.org/10.1037/a0026947

Turakulov Y, Burikhanov RB, Patkhitdinov PP, Myslitskaya AI. Influence of immobilization stress on the level of secretion of thyroid hormones. Neurosci Behav Physiol 1994; 24: 462-4. https://doi.org/10.1007/BF02360166

van den Briel T, West CE, Bleichrodt N, van de Vijver FJ, Ategbo EA, Hautvast JG. Improved iodine status is associated with improved mental performance of schoolchildren in benin. Am J Clin Nutr 2000; 72: 1179-85. https://doi. org/10.1093/ajen/72.5.1179
WHO. Assessment of iodine deficiency disorders and monitoring their elimination: a guide for programme managers: Geneva: World Health Organization, 2001.

Yaribeygi H, Panahi Y, Sahraei H, Johnston TP, Sahebkar A. The impact of stress on body function: a review. EXCLI J 2017; 16: 1057-72.

Zimmermann MB. Iodine deficiency in pregnancy and the effects of maternal iodine supplementation on the offspring: a review. Am J Clin Nutr 2009; 89: 668s-72s. https://doi. org/10.3945/ajen.2008.26811C

Zimmermann MB, Andersson M. Assessment of iodine nutrition in populations: past, present, and future. Nutr Rev 2012; 70: 553-70. https://doi.org/10.1111/j.17534887.2012.00528.x 